\title{
Structural studies with the use of XRD and Mössbauer spectroscopy of new high Manganese steels
}

\author{
Magdalena Barbara Jablonska
}

Published online: 7 November 2013

(C) The Author(s) 2013. This article is published with open access at Springerlink.com

\begin{abstract}
New high-strength austenitic and austenitic-ferritic manganese steels represent a significant potential in applications for structural components in the automotive and railway industry due to the excellent combination of high mechanical properties and good plasticity. They belong to the group of steels called AHSS (Advanced High Strength Steels) and UHSS (Ultra High Strength Steels). Application of this combination of properties allows a reduction in the weight of vehicles by the use of reduced cross-section components, and thus to reduce fuel consumption. The development and implementation of industrial production of such interesting and promising steel and its use as construction material requires an improvement of their casting properties and susceptibility to deformation in plastic working conditions. In this work, XRD, Transmission Mössbauer Spectroscopy and Conversion Electron Mössbauer Spectroscopy were employed in a study of the new high-manganese steels with a austenite and austenite-ferrite structure. The influence of the plastic deformation parameters on the changes in the structure, distribution of ferrite and disclosure of the presence of carbides was determined. The analysis of phase transformations in various times using CEMS method made possible to reveal their fine details.
\end{abstract}

Keywords High manganese steels • rolling • structural studies • Mössbauer spectroscopy

Proceedings of the 32nd International Conference on the Applications of the Mössbauer Effect (ICAME 2013) held in Opatija, Croatia, 1-6 September 2013.

M. B. Jablonska ( $\square)$

Silesian University of Technology, Gliwice, Poland

e-mail: magdalena.jablonska@polsl.pl 
Table 1 Chemical composition of the researched steels [wt. \%]

\begin{tabular}{lllllllllllllll}
\hline \multicolumn{1}{c}{ Chemical composition } & \multicolumn{1}{c}{ C } & C & Mn & Al & Si & P & S & Mo & B & Ce & La & Nd & $\begin{array}{l}\text { N } \\
\text { ppm }\end{array}$ \\
& & & & & & & & & & & & \\
\hline X60MnAl30-9 & 0.67 & 29.0 & 9.0 & 0.4 & $<0.01$ & $<0.006$ & 0.19 & $<0.001$ & 0.023 & 0.009 & 0.011 & 18 \\
X55MnA125-5 & 0.53 & 25.0 & 5.0 & 0.34 & 0.01 & $<0.006$ & 0.16 & $<0.001$ & 0.009 & 0.002 & 0.003 & 29 \\
\hline
\end{tabular}

\section{Introduction}

In recent years, research centers worldwide are focusing their investigations in the area of development of high manganese steel for the automotive industry. Depending on their contents of $\mathrm{Mn}, \mathrm{Al}$ and $\mathrm{Si}$, these steels have different properties and therefore a unique deformation mechanisms, such as a Twinning Induced Plasticity (TWIP effect) and the Micro Bands Induced Plasticity (MBIP effect) [1-4]. Am advantageous combination of strength and plastic properties and a very high ability of energy absorption in the deformation process, resulting from the deformation mechanism in these steels suggest to presume that the possibility of their use in the construction of transport means will become more common. These steels are already competitive to traditional metallic materials currently used. A synergy of mechanical properties occurring in these steels is a new quality in the branch of steel construction materials. The demand for such materials increases with increasingly rigorous standards for construction vehicles and strict crash test conditions, because of the stress laid on the safety of users of motor vehicles [5-7]. Structural elements made of these steels are usually produced by thermal treatment methods of forming, prompting an analysis of the impact of the process parameters on the structure and properties of these steels [6-11].

In this work, XRD, Transsmision Mössbauer Spectroscopy and Conversion Electron Mössbauer Spectroscopy were employed in a study of new high-manganese steels with an austenite and austenite-ferrite structure. The influence of the plastic deformation parameters on the changes in the structure, distribution of ferrite and disclosure of the presence of carbides was determined. The analysis of phase transformations in various times using CEMS method made possible to reveal their fine details.

\section{Materials and testing methods}

The material consisted of two types of high manganese steel with different content of carbon, manganese and aluminum. Their chemical compositions according to the ladle analysis are shown in Table 1. Production technology of the investigated steels was developed for melting in a VSG $100 \mathrm{~S}$ vacuum induction furnace from PVA TEPLA AG which created favorable conditions for the desired composition, narrow ranges of contents of the individual elements, as well as the required high metallurgical purity of the steel. Restrictions on dopant elements mainly concerned $\mathrm{S}$ content that should not exceed $0.01 \%$, and it was desirable that this content was minimized. Requirements related to the addition of mischmetal in an amount of $1.0 \mathrm{~g}$ per $1 \mathrm{~kg}$ of steel $(0.1 \%)$. 
The casting process was conducted in an atmosphere of argon, with the heated tundish to a properly prepared water cooled copper crystallizer, with a square crosssection of $100 \times 100 \mathrm{~mm}$ and a height of $1100 \mathrm{~mm}$. The crystallizer had an insulating insert The crystallizer is used to simulate the process of continuous casting of steel (COS), which is the least energy-consuming process for the production of steel, and also significantly increases the yield during of the obtained steel. The ingots were cooled for $2 \mathrm{~h}$ in the closed furnace under Ar atmosphere, in order to minimize oxidation of the steel in the crystallizer. The steel from the crystallizer was rolled into square shapes with a diagonal of $45 \mathrm{~mm}$, then into the bars with a diameter of $12 \mathrm{~mm}$. The temperature for the steel heating was selected as $1150 \rightarrow 900{ }^{\circ} \mathrm{C}$ on the basis of plastic properties including chemical composition, properties depending on processing temperature, and requirements for the final product. After the rolling, the rods made of X55MnAl25-5 steel were cooled by air and those of X60MnAl30-9 were cooled by air and a regulated water cooling system.

Structural studies were carried out on samples cut from the supplied rods. Analysis of the microstructure was carried out after etching in $10 \%$ Nital. X-ray phase analysis was performed on a JEOL JDX-7S X-ray diffractometer, using a lamp with a copper anode $(\lambda \mathrm{CuK} \alpha=1.54178 \AA)$ powered by a current of $20 \mathrm{~mA}$ at a voltage of $40 \mathrm{kV}$, and a graphite monochromator. Recording of the results was carried out stepwise with a step of $0.05^{\circ}$ and counting time of $5 \mathrm{~s}$ in the range from 20 to $100^{\circ} 2 \theta$. Solid samples were studied.

The measurements of the ${ }^{57} \mathrm{Fe}$ Mössbauer spectra were performed in transmission geometry by means of a constant spectrometer of the standard design. The $14.4 \mathrm{keV}$ gamma rays were provided by a $50 \mathrm{mCi}$ source of $57 \mathrm{Co} / \mathrm{Rh}$. The spectra of the samples were measured at room temperature. Isomeric shifts of the investigated spectra were related to the $\alpha$-Fe standard. For the study, Conversion Electron Mössbauer Spectroscopy (CEMS) with gas detector, filled with $98 \% \mathrm{He}+2 \%$ Ar, under pressure of 0.9 at., was applied. ${ }^{57} \mathrm{CoRh}$ with activity of $10 \mathrm{mCi}$ was a Mössbauer source. Application of CEMS technique allowed to investigate the surface layers with thickness of about $100 \mathrm{~nm}$.

\section{Results and discussion}

X-ray diffraction patterns of the samples are shown in Figs. 1 and 2. X55MnA1255 steel revealed the presence of austenite $(\gamma-\mathrm{Fe})$. The samples of X60MnAl30-9 steel were found to contain austenite $(\gamma-\mathrm{Fe})$ and ferrite $(\alpha-\mathrm{Fe})$. The microstructure of the X55MnAl25-5 steel revealed the presence of austenite grains with typical annealing twins and deformation twins. During microscopic observation of the X60MnAl30-9 steel, austenitic-ferritic structure was found. Elongated ferrite grains in the rolling direction were observed. Ferrite grains are characterized by varied size and morphology of the cross section.

All the designated Mössbauer spectra may be described by:

1. Magnetic (Zeeman) components of the ferritic phase or the additional phase that may be attributed to carbides. Parameters of the component spectra of ferritic and austenitic phases (especially those of the hyperfine magnetic field $\mathrm{H}$ ) depend on the number and position of carbon atoms (tetrahedral or octahedral environment) in the immediate neighborhood of the iron atom. The following 


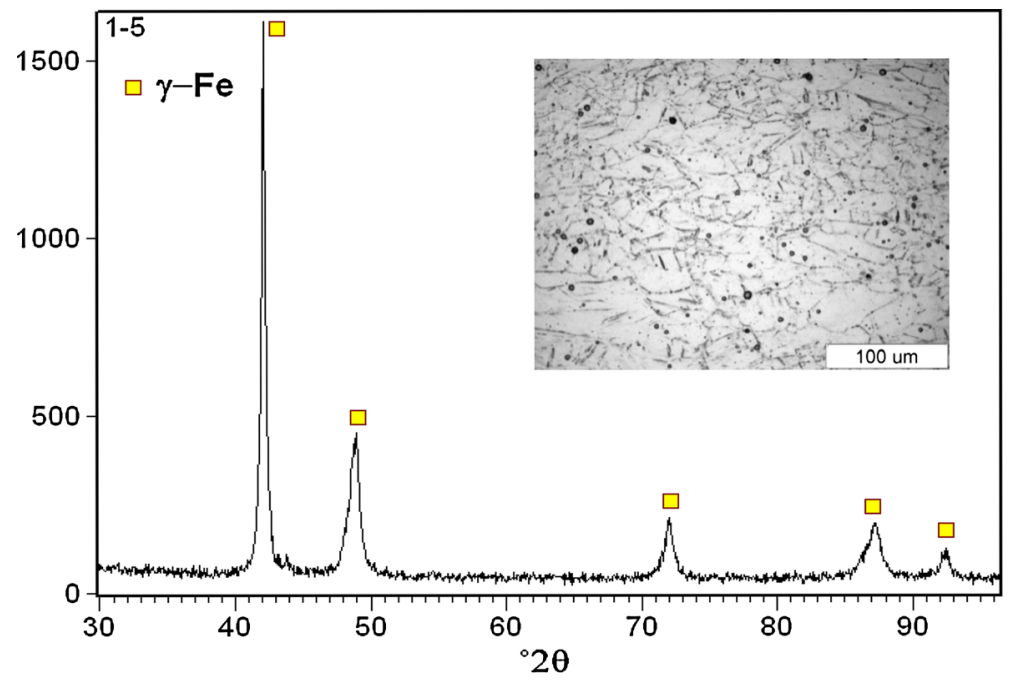

Fig. 1 Results of X-ray diffraction and microstructural analysis for the X55MnAl25-5 steel after air cooling.

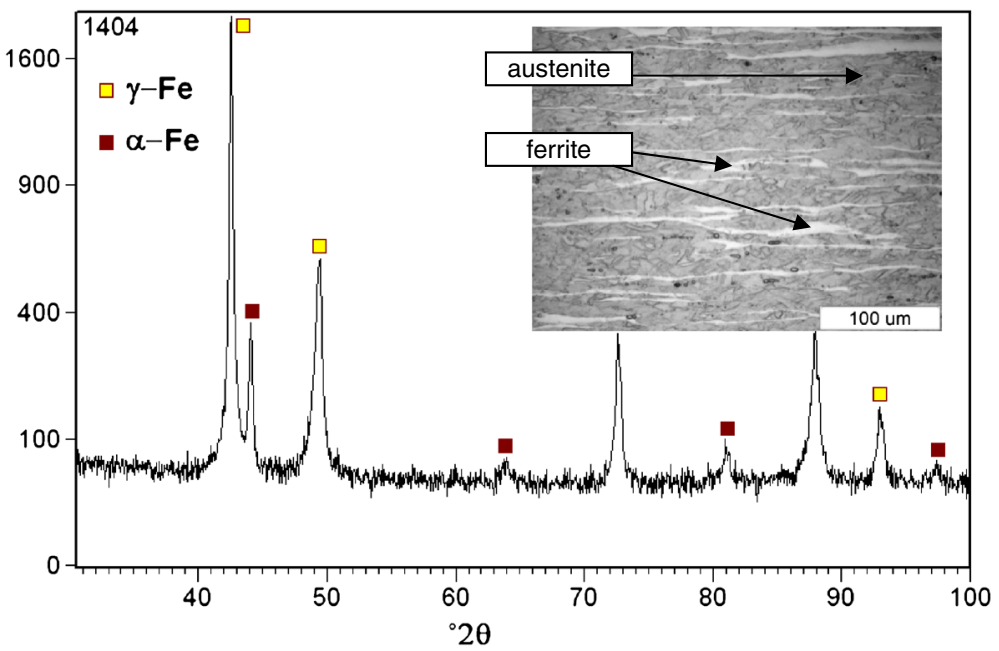

Fig. 2 Results of X-ray diffraction and microstructural analysis for the X60MnAl30-9 steel after air cooling

specific types of $\mathrm{Fe}$ atoms may be distinguished: $\mathrm{Fe}_{0}-\mathrm{Fe}$ atoms which do not have a carbon atom in their close neighborhood $(H \approx 330 \mathrm{kGs}) ; \mathrm{Fe}_{\mathrm{nn}}-\mathrm{Fe}$ atoms having one $\mathrm{C}$ atom in the octahedral position in their close neighborhood $(H \approx$ $275 \mathrm{kGs}) ; \mathrm{Fe}_{\mathrm{nnn}}-\mathrm{Fe}$ atoms having one $\mathrm{C}$ atom in the octahedral position in their farther neighborhood $(H \approx 305 \mathrm{kGs})$. 

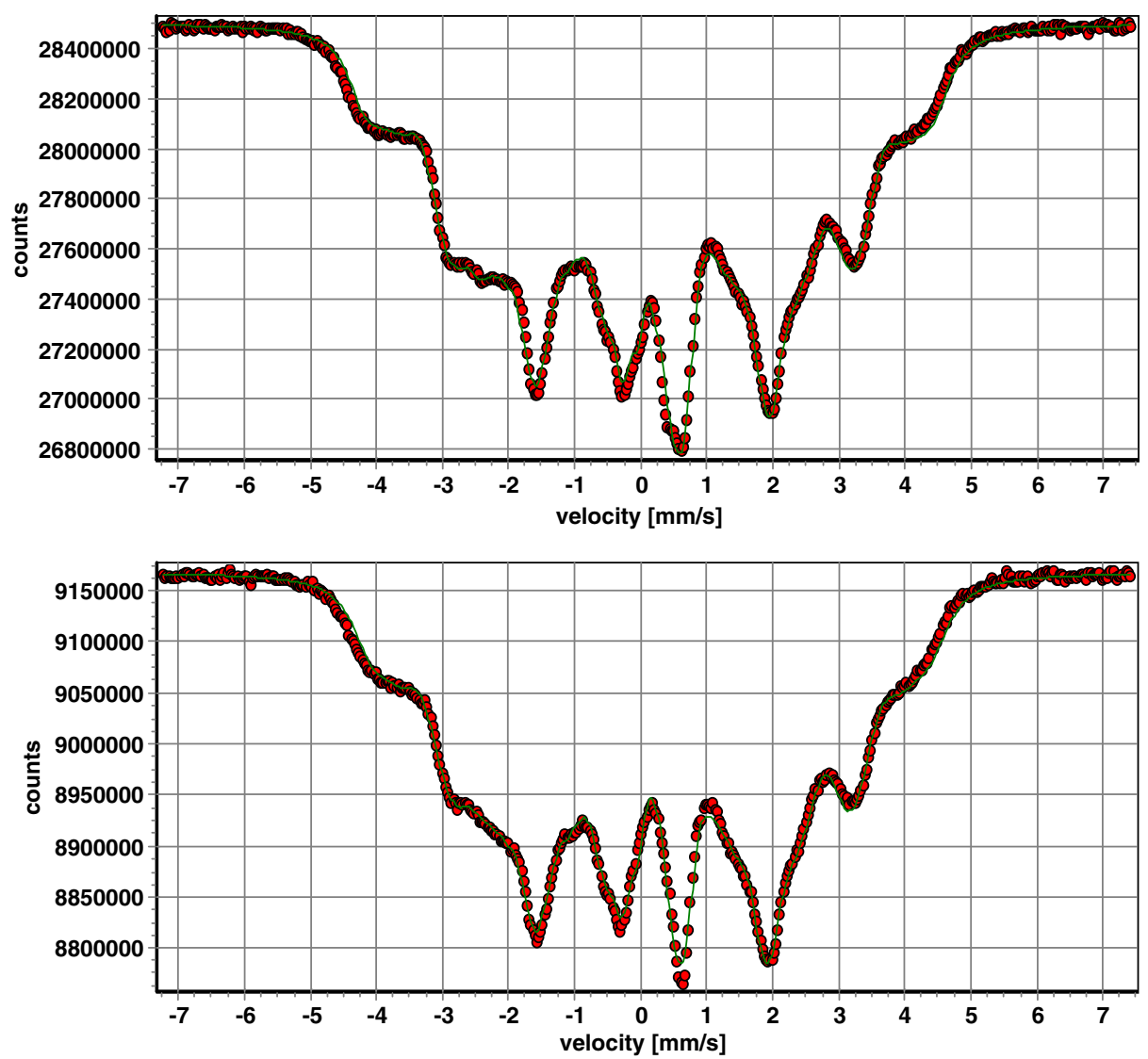

Fig. 3 Mössbauer spectra for the X55MnA125-5 steel. Mössbauer spectra for the X60MnAl30-9 steel

The average literature values for the $\mathrm{H}-\mathrm{Fe}-\mathrm{C}$ are cited, introduction of additives causes their changes. The hyperfine magnetic field $\mathrm{H}$ for $\mathrm{Fe}_{2} \mathrm{C}$ carbide is of the order of $230 \div 240 \mathrm{kGs}$, while that for $\mathrm{Fe}_{3} \mathrm{C}$ cementite amounts to $200 \mathrm{kGs}$.

2. A component in the form of a sum of a single line and a quadrupole doublet, which may be assigned to the austenitic phase. The single peak is related to $\mathrm{Fe}$ atoms which do not have a carbon atom in their close neighborhood (IS $=-0.1 \mathrm{~mm} / \mathrm{s}$ ), while the quadrupole doublet, with positive values of the isomeric shift IS, is related to the Fe atoms that have carbon atoms in their close neighborhood.

The parameters of the component spectra were determined on the basis of the MOSDS software. The following notation is used: $\mathrm{H}$ - effective magnetic field, IS isomeric shift, QS - quadrupole splitting, A2 - the ratio of intensities of 2/3 lines in the Zeeman spectrum, $\mathrm{S}$ - intensity of a spectral component, $\mathrm{Z}_{\mathrm{i}}$-the Zeeman components, $\mathrm{Q}$ - component of the quadrupole, and L - Lorentz component (single line). 
Fig. 4 Mössbauer results obtained by the CEMS technique for the X55MnA125-5 steel

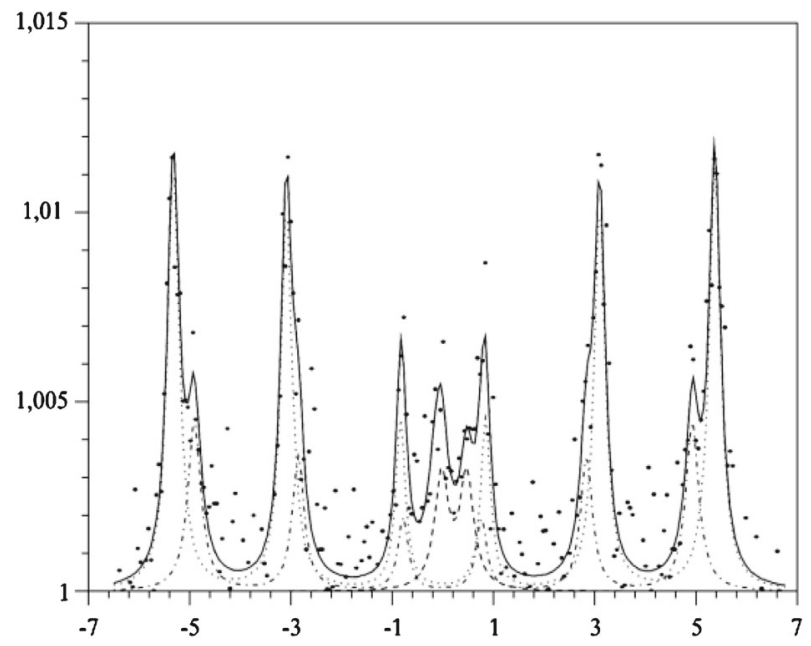

Magnetic (Zeeman) components characterizing phases that should be expected in the studied material, are described by the following hyperfine parameters: for ferrite - the field strength $\mathrm{H}$ of 300 to $330 \mathrm{kGs}$ and isomeric shift IS up to $0.02 \mathrm{~mm} / \mathrm{s}$; for martensite-the field strength $\mathrm{H}$ of 240 to $270 \mathrm{kGs}$, the isomeric shift IS from -0.01 to $+0.04 \mathrm{~mm} / \mathrm{s}$, QS up to $0.02 \mathrm{~mm} / \mathrm{s}$; for $\mathrm{Fe}_{3} \mathrm{C}$ cementite-the field strength $\mathrm{H}$ of the order of $200 \mathrm{kGs}$; for $\mathrm{Fe}_{2} \mathrm{C}$ carbide-the field strength $\mathrm{H}$ of 230 to $240 \mathrm{kGs}$.

Non-magnetic components of austenite are as follows: IS from -0.1 to $-0.2 \mathrm{~mm} / \mathrm{s}$ and QS from 0.2 to $0.4 \mathrm{~mm} / \mathrm{s}$.

The value of the hyperfine magnetic field $\mathrm{H}$ is dependent on the number of Fe atoms in the local neighborhood of the Mössbauer nuclide, and the higher this number in a given structure, the higher the value. This fact allows for distinguishing the phases of the same crystal structure but different magneto-electronic structure, as in the case of $\alpha 1$ and $\alpha 2$ ferrites.

Examples of spectra measured using the transmission technique for the two test samples of the steels after cooling after rolling in the air, with their attributions are shown in Figs. 3 and 4. Figure 3 shows the results obtained using the Mössbauer transmission technique for the X55MnAl25-5 steel. Figure 4 shows the results obtained using the Mössbauer transmission technique for the X60MnAl30-9 steel. Figure 5 shows the Mössbauer results obtained by the CEMS technique for both steels after air and water cooling.

On the basis of the Mössbauer results and the analysis of the values of the parameters IS, QS, and $\mathrm{H}$, it was found that the spectral component $\mathrm{Z} 1$ originated from the ${ }^{57} \mathrm{Fe}$ atoms contained in the structure of $\alpha 1$ ferrite. Z2 component-from $\alpha 2$ ferrite, a Z3 component derived-from ${ }^{57} \mathrm{Fe}$ located in the structure of carbides. However, an analysis of the parameters describing the non-magnetic components $(\mathrm{L}+\mathrm{Q})$ indicates that they characterize a stable austenite $\gamma$, oversaturated with carbon. The differences in values for H, IS and QS for the specified component may be due to their different morphology, the effects of field strength $\mathrm{H}$ from $\alpha 1$ and $\alpha 2$ ferrites, and $\gamma$ austenite presence. Three phases such as austenite, ferrite, and carbides were obtained with shares depending on the cooling rate after rolling. 
Fig. 5 Mössbauer results obtained by the CEMS technique for the X60MnAl30-9 steel
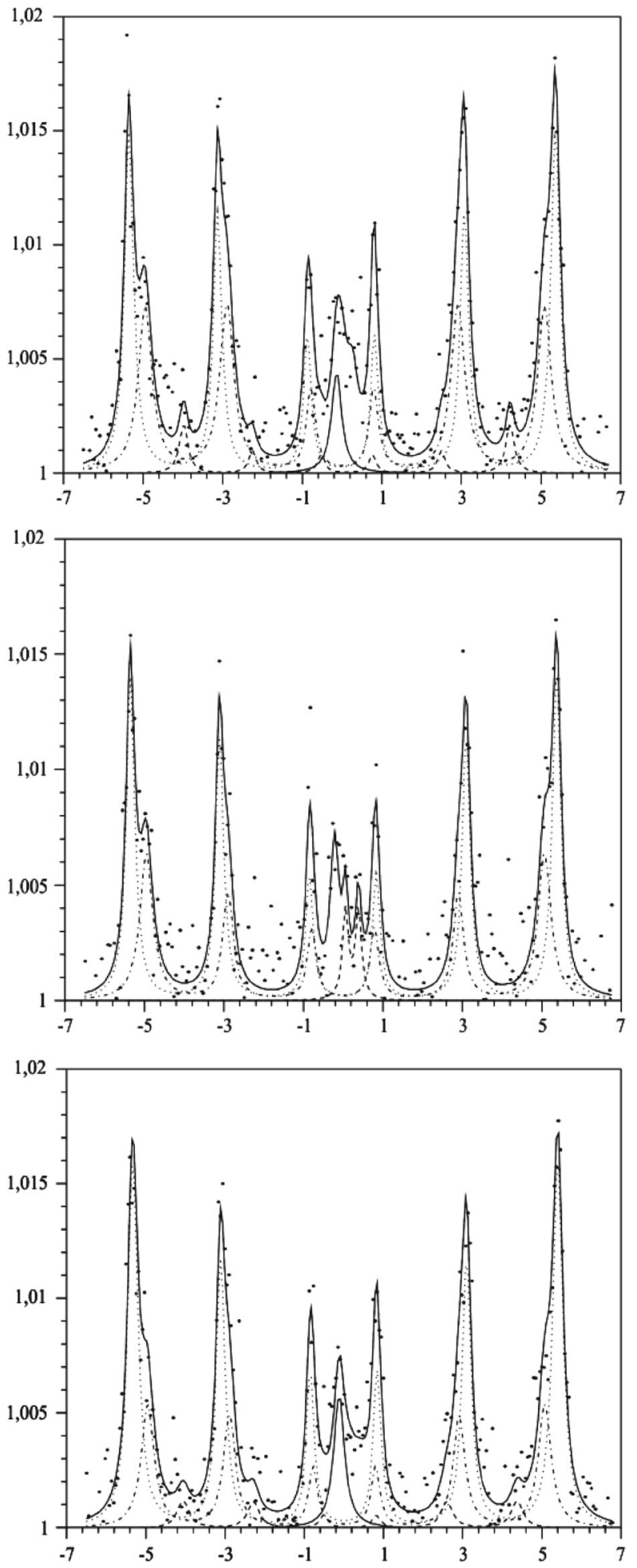
Table 2 The results of Mössbauer spectra with the determination of the phase composition for the $\mathrm{X} 55 \mathrm{MnAl} 25-5$ steel

\begin{tabular}{rlllllll}
\hline Sample & $\begin{array}{l}\text { Spectral } \\
\text { component }\end{array}$ & $\begin{array}{l}\mathrm{H} \\
\mathrm{kGs}\end{array}$ & $\begin{array}{l}\mathrm{IS} \\
\mathrm{mm} / \mathrm{s}\end{array}$ & $\begin{array}{l}\mathrm{QS} \\
\mathrm{mm} / \mathrm{s}\end{array}$ & $\mathrm{S}-$ & $\begin{array}{l}\text { Phase } \\
\text { composition }\end{array}$ & $\begin{array}{l}\text { Amount } \\
\%\end{array}$ \\
\hline $\begin{array}{r}\text { After air } \\
\text { cooling }\end{array}$ & $\mathrm{Z} 1$ & 294.0 & 0.032 & 0.011 & 0.11 & $\begin{array}{l}\alpha_{l} \text { ferrite or } \\
\alpha_{2} \text { ferrite }\end{array}$ & 11 \\
& $\mathrm{Q}$ & - & 0.18 & 0.276 & 0.08 & $\begin{array}{l}\text { Austenite } \\
89\end{array}$ & \\
& $\mathrm{~L}$ & - & -0.12 & - & 0.06 & & \\
& $\mathrm{~L}$ & - & -0.09 & - & 0.04 & & \\
\hline
\end{tabular}

These values were calculated with the following ranges of error $\Delta \mathrm{H}= \pm 0,2 \mathrm{kGs}, \Delta \mathrm{IS}=\Delta \mathrm{QS}=$ $\pm 0,002 \mathrm{~mm} / \mathrm{s}$ i $\Delta \mathrm{S}= \pm 0,2$

Table 3 The results of Mössbauer spectra with the determination of the phase composition for the X60MnAl30-9 steel

\begin{tabular}{llllllll}
\hline Sample & $\begin{array}{l}\text { Spectral } \\
\text { component }\end{array}$ & $\begin{array}{l}\mathrm{H} \\
\mathrm{kGs}\end{array}$ & $\begin{array}{l}\mathrm{IS} \\
\mathrm{mm} / \mathrm{s}\end{array}$ & $\begin{array}{l}\mathrm{QS} \\
\mathrm{mm} / \mathrm{s}\end{array}$ & $\begin{array}{l}\mathrm{S}- \\
\text { Phase } \\
\text { composition }\end{array}$ & $\begin{array}{l}\text { Amount } \\
\%\end{array}$ \\
\hline After air & $\mathrm{Z} 1$ & 287.0 & 0.032 & 0.011 & 0.11 & $\alpha_{l}$ ferrite or $\alpha_{2}$ ferrite & 28 \\
cooling & $\mathrm{Q}$ & - & 0.18 & 0.276 & 0.08 & Austenite & 72 \\
& $\mathrm{~L}$ & - & -0.12 & - & 0.06 & & \\
After regulated & $\mathrm{Z} 1$ & 279.2 & 0.032 & 0.014 & 0.12 & $\alpha_{l}$ ferrite or $\alpha_{2}$ ferrite & 32 \\
water flow & $\mathrm{Z} 2$ & 190.6 & 0.14 & 0.03 & 0.05 & Carbides & 29 \\
& $\mathrm{Q}$ & - & 0.19 & 0.48 & 0.14 & Austenite & 39 \\
After water & $\mathrm{L}$ & - & -0.14 & - & 0.06 & & \\
cooling & $\mathrm{Z} 1$ & 294.6 & 0.03 & 0.021 & 0.14 & $\alpha_{l}$ ferrite or $\alpha_{2}$ ferrite & 32 \\
& $\mathrm{Z} 2$ & 262.1 & 0.16 & 0.024 & 0.06 & Carbides & 32 \\
& $\mathrm{Q}$ & - & 0.13 & 0.191 & 0.31 & Austenite & 36 \\
& $\mathrm{~L}$ & - & -0.09 & - & 0.04 & & \\
\hline
\end{tabular}

This indicates a possible impact of the cooling rate on the phase composition of the investigated steel. The results of the hyperfine parameters and phase composition of the remaining test samples are gathered in Tables 2 and 3.

\section{Summary}

On the basis of the studies carried out in transmission geometry, phase composition of steel test samples has been analyzed. It has been found that in the test samples of the examined steels, austenitic phase prevails. The remaining phase for the X55MnAl25-5 steel is ferrite. For the X60MnAl30-9 steel, presence of three phases (such as austenite, ferrite, and carbides) independently of the cooling process after rolling is ascertained. The studies conversion Electron Mössbauer Spectroscopy CEMS show the impact of the method used for cooling after rolling on the structure. Given the limited spectral statistics, these results are in a good accordance with the $\mathrm{X}$-ray results.

Acknowledgement The author would like to thank Dr Aneta Hanc for supporting the research, leading to this results. 
Open Access This article is distributed under the terms of the Creative Commons Attribution License which permits any use, distribution, and reproduction in any medium, provided the original author(s) and the source are credited.

\section{References}

1. Grässel, O., Krüger, L., Frommeyer, G., Meyer, L.W.: High strength Fe-Mn-(Al, Si) TRIP/TWIP steels developments properties-application. Int. J. Plast. 16, 1391-1409 (2000)

2. Frommeyerr, G., Brux, U., Neumann, P.: Supra-ductile and high-strength manganeseTRIP/TWIP steels for high energy absorption purposes. ISIJ Int. 43, 438-446 (2003)

3. Frommeyerr, G., Brux, U.: Microstructures and mechanical properties of high-strenght FeMnAl-C Light TRIPLEX steels. Steel Res. Int. 77, 627-633 (2006)

4. Scott, C., Allain, S., Faral, M., Guelton, N.: The development of a new Fe-Mn-C austenitic steel for automotive applications. Rev. Metall. 6, 293-302 (2006)

5. Hamada, S.A.: Manufacturing, Mechanical Properties and Corrosion Behaviour of High Mn Twip Steels. Acta Universitatis Ouluensis C281 (2007)

6. Hofmann, H., Menne, M., Göklü, S., Richter, H.: Properties of austenitic high manganese steels with induced plasticity (LIP steels). In: Proc. of Int. Conf. on Steel Future for the Automotive Industry, pp. 73-80. Wiesbaden, Germany (2005)

7. Grajcar, A., Borek, W.: Thermo-mechanical processing of high-manganese austenitic TWIP-type steels. Arch. Civil Mech. Eng. VIII(4), 29-38 (2008)

8. Wiewiórowska, S.: The influence of strain rate and strain intensity on retained austenite content in structure of steel with TRIP effect. Solid State Phenom. 165, 216-220 (2010)

9. Jabłońska, M., Ňmiglewicz, A.: Analysis of substructure of high-Mn steels in the context of dominant stress mechanism. Defect Diff. Forum. 334-335, 177-181 (2013)

10. Jabłońska, M., Śmiglewicz, A., Niewielski, G., Hetmańczyk, M.: Heat treatment of high manganese type X57MnAl27-5 austenitic steel. Mater. Sci. Eng. Conf. Series 22, 012015 (2011)

11. Tomaszewska, A., Jabłońska, M., Hadasik, E., Niewielski, G., Kawalla, R.: Research of selected properties of two types of high manganese steel wires. Mater. Sci. Eng. Conf. Series 22, 012014 (2011) 